\title{
Una revisión de la teoría de Análisis Transaccional y posibles aplicaciones en la educación desde Orientación
}

\section{A Review of the transactional analysis and the possible applications in the educational field form counseling}

\author{
María Luisa Naranjo Pereira \\ Docente de la Escuela de Orientación y Educación Especial \\ Universidad de Costa Rica \\ San José, Costa Rica \\ malunape@gmail.com
}

Recibido: 18-IX-2010 • Aceptado 05-X-2010 • Corregido 21-VI-2011

\begin{abstract}
Resumen: Este artículo presenta una breve referencia biográfica del creador de la teoría de Análisis Transaccional, Eric Berne. Se analizan las características que distinguen esta teoría y su relación con otros enfoques teóricos. Se estudian los cuatro tipos de análisis que ella incluye: a) el análisis estructural y funcional de la personalidad y las patologías asociadas a su estructura; b) el análisis de transacciones y la comunicación humana; c) el análisis de juegos psicológicos, los papeles que se desempeñan en estos, sus características y la fórmula que sigue el desarrollo de esos juegos; $y$ d) el análisis de los guiones de vida, la importancia de mensajes y mandatos recibidos para la conformación del guión y del mito personal, los mensajes que impulsan el guión y formas para abandonarlo. Se abordan, además, otros temas relevantes en esta teoría como son: las posiciones existenciales que asumen las personas sobre sí mismas, las otras y la vida; el papel de las emociones y su clasificación y la necesidad de caricias positivas para la supervivencia biológica y psicológica del ser humano. Después del análisis teórico se presenta un apartado con aportes basados en el Análisis Transaccional que pueden ser aplicados desde la Orientación en las instituciones educativas.
\end{abstract}

\section{Introducción}

El Análisis Transaccional además de ser una teoría de la personalidad, es una teoría de la comunicación que permite comprender y mejorar la calidad de las relaciones interpersonales. Del mismo modo, facilita entender las influencias del entorno, esto es, de las personas e instituciones sociales que participan en el proceso de socialización, en la conformación de la estructura y el funcionamiento de la personalidad. Esta teoría explica cómo a partir de los tipos de mensajes, caricias, mandatos, prohibiciones y permisos que la persona recibe desde etapas muy tempranas de su vida, ella toma decisiones sobre quién es y cómo debe ser, adoptando determinadas posiciones existenciales o percepciones sobre sí misma, las otras personas y la vida. 
Palabras clave: Análisis Transaccional, Orientación, Educación.

\begin{abstract}
This article presents a brief biographic reference of the Transactional Analysis creator, Eric Berne. The characteristics that distinguish this theory and the relationship with other theoretical approaches are analyzed. Four types of analysis are studied: a) the structural and functional analysis of the personality and the pathologies associated to the structure; b) the transactions and the human communication; c) the psychological games analysis, the roles played in this ones, their characteristics and the formula that follows the development of those games; d) the life scripts analysis, the importance of the messages and orders received for the conformation of the personal script and myth, the messages that pushes the script and ways to abandon it. Other relevant themes are approach such as: the existential positions that the persons assume about themselves, the others and life; the role of emotions and it's qualification and the necessity of positives caress for biological and psychological human survival. After the theoretical analysis it's presented a section with Transactional Analysis contributions that can be implemented in educational institutions by the counseling department.
\end{abstract}

Keywords: Transactional Analysis, Counseling, Education
A partir de estas decisiones y percepciones, actúa en concordancia tanto consigo misma como con las demás, estableciendo relaciones saludables o enfermizas con estas o participando en juegos psicológicos que le permiten mantener o reforzar sus posiciones existenciales.

En síntesis, a partir de las influencias del entorno (familia, educación, religión, sociedad como un todo) del tipo de mensajes y caricias recibidas, de las decisiones que tome respecto de quién es y de las posiciones existenciales que asuma, la persona va elaborando y viviendo su guión o guiones de vida. El problema es que muchas veces desarrolla un "mito" sobre ella misma, basado en mensajes falsos y caricias negativas que la llevan a vivir guiones destructivos que sostiene mediante relaciones interpersonales nocivas y juegos psicológicos.

De acuerdo con lo mencionado, la aplicación del Análisis Transaccional se torna relevante por cuanto permite que la persona conozca cómo está estructurada su personalidad y cómo funciona, que tome conciencia de los mensajes recibidos a lo largo de su historia de vida que han influido en la conformación de su personalidad y en sus posiciones existenciales y que analice el tipo de transacciones que comúnmente mantiene con otras personas; además, proporciona la oportunidad de que descubra aquellos juegos psicológicos en los que participa, qué tipo de caricias espera obtener mediante esos juegos y el porqué; finalmente, da la oportunidad de que pueda tomar conciencia del tipo o tipos de guiones que está viviendo.

Al tener claros todos esos aspectos, la persona puede volver a decidir sobre sí misma, desechando el "mito" personal para encontrar su verdadero yo, y así modificar su percepción o posición existencial para adoptar una más sana: "yo estoy bien y tú estás bien"; asimismo, puede abandonar juegos psicológicos y buscar formas más sanas de dar y obtener caricias, lo cual le permitirá mejorar sus relaciones interpersonales 
y dejar guiones de vida predeterminados, reconociendo su poder para definir su proyecto existencial y convertirse de esta forma en autor y protagonista real de su vida.

El propósito último del Análisis Transaccional es que la persona llegue a ser autónoma, lo que significa que está interesada básicamente en ser ella misma, en plantearse metas realistas que den propósito y significado a su existencia y en desarrollar un sistema ético para aplicarlo a su vida y en la toma de decisiones.

De acuerdo con lo planteado, resulta necesario revisar todos los temas centrales que trata esta teoría, a saber:

Análisis estructural de la personalidad

Análisis funcional de la personalidad

Posiciones existenciales

Las emociones en el Análisis Transaccional

Necesidad y tipos de caricias

Análisis transaccional y comunicación humana

Análisis de juegos psicológicos

Análisis de guiones o dramas de la vida

En cuanto a la organización de este artículo, se presenta inicialmente una referencia biográfica sobre el autor de la teoría en estudio, luego se revisan las características del Análisis Transaccional y su relación con otros enfoques, posteriormente se sigue el orden de los temas antes mencionados para una mejor comprensión y se finaliza con los aportes que la teoría puede brindar en el ámbito educativo aplicados desde la disciplina de la Orientación.

\section{Sobre el creador del Análisis Transaccional}

Eric Berne, cuyo nombre original era Eric Lennar Bernstein, nació en Montreal, Canadá en 1910 y falleció el 15 de julio de 1970 a los sesenta años. Su padre era médico y su madre escritora. Cuando tenía diez años fallece su padre y, siguiendo los pasos de este, a los veinticinco años termina sus estudios de Medicina en la Universidad de Mc Gill en Montreal. Posteriormente, a los veintinueve años emigra a Estados Unidos y adopta esa nacionalidad, cambiando su apellido por Berne.

\section{Características del Análisis Transaccional y su relación con otros enfoques}

Con el propósito de lograr una mejor comprensión de esta teoría, resulta de mucha importancia conocer las características que la distinguen y que la convierten en una teoría amplia, flexible e integral. Estas características a su vez permiten que al ponerla en práctica pueda ser complementada y profundizada con los aportes que brindan otros enfoque teóricos. A continuación se presenta este análisis.

-Esta teoría se basa en una filosofía positiva y de confianza en el ser humano. Considera que todas las personas tienen el mismo valor como seres humanos. Lo que puede variar son las conductas, algunas de las cuales pueden ser adecuadas y otras no. Sobre este aspecto del valor humano, según el enfoque de la Terapia Racional Emotivo-Conductual y de acuerdo con Ellis, en Naranjo (2004), el concepto de bueno no puede aplicarse al ser humano. Es decir, no se requiere que la persona actúe bien y realice todo con éxito para que sea juzgado como valioso. Por ello, se le acepta incondicionalmente, no importa que ciertos de sus actos sean calificados por ella misma o por otras como equivocados o tontos, o por el hecho de que los demás la acepten o condenen. Este autor, por lo tanto, subraya el valor del ser humano solo por el hecho de estar vivo y añade que aunque una existencia puede no ser del todo satisfactoria, siempre hay posibilidad de que lo sea.

La mejor estrategia para el manejo de problemas relacionados con el valor humano consiste en separar el problema o hecho del autor, de esta forma se reacciona ante el comportamiento apropiado 
o inapropiado, sin dar opiniones sobre el valor de la persona.

Los modelos humanísticos existenciales coinciden con esa filosofía positiva del ser humano. Como parte de sus principios básicos, de acuerdo con Feixas y Miró (1993), se señala la autorrealización, que se concibe como una tendencia inherente al organismo que lo impulsa hacia el crecimiento, la diferenciación y la búsqueda de sentido, entendido como el énfasis en el carácter intencional de la acción humana. Se sostiene que la persona no solo se mueve por motivaciones materiales, sino también por principios axiológicos, tales como la libertad, la justicia y la dignidad, que suponen el intento de trascender la propia existencia.

Él era neuropsiquiatra y fue alumno de Erik Erikson. Dos hechos importantes influyeron en la creación de su obra, primero, cuando trabajando con el Dr. Pendfiel, quien era cirujano, lo impactó su descubrimiento de que cualquier hecho observable que se registra en el cerebro se asocia a un sentimiento y cuando posteriormente se evoca ese hecho, no aparece solo, sino acompañado por el sentimiento original con el que estuvo asociado. Segundo, al observar en su práctica como psicoterapeuta que en las personas se producen cambios en su comportamiento, incluyendo expresiones faciales, entonaciones de la voz, movimientos y posturas corporales e incluso formas de caminar si se les presenta un nuevo estímulo, como una palabra o un sonido. Era como si en una misma persona convivieran varias, cada una de las cuales se manifestaba según la situación.

A partir de esas observaciones, elabora su modelo de los estados del yo y de las transacciones que ocurren entre estos. Berne (1983) manifiesta que: "El Análisis Transaccional no pretende ser una nueva enunciación de la psicología freudiana, junguiana o de cualquier otra. El superyó, el yo y el ello son conceptos, en tanto que los estados del yo son realidades vivenciales y de comportamiento...” (p. 245).
En 1941 publica su primer libro: Los mecanismos de la mente. Su primer libro sobre Análisis Transaccional propiamente, se publica en 1961: Análisis Transaccional en Psicoterapia. En 1964 publica: Juegos en que participamos. Psicología de las relaciones humanas y en 1970: Hacer el amor. También escribió el libro: ¿Qué dice usted después de decir hola?, el cual se publicó en 1972.

\section{Características del Análisis Transaccional y su relación con otros enfoques}

Con el propósito de lograr una mejor comprensión de esta teoría, resulta de mucha importancia conocer las características que la distinguen y que la convierten en una teoría amplia, flexible e integral. Estas características a su vez permiten que al ponerla en práctica pueda ser complementada y profundizada con los aportes que brindan otros enfoque teóricos. A continuación se presenta este análisis.

-Esta teoría se basa en una filosofía positiva y de confianza en el serhumano. Considera que todas las personas tienen el mismo valor como seres humanos. Lo que puede variar son las conductas, algunas de las cuales pueden ser adecuadas y otras no. Sobre este aspecto del valor humano, según el enfoque de la Terapia Racional Emotivo-Conductual y de acuerdo con Ellis, en Naranjo (2004), el concepto de bueno no puede aplicarse al ser humano. Es decir, no se requiere que la persona actúe bien y realice todo con éxito para que sea juzgado como valioso. Por ello, se le acepta incondicionalmente, no importa que ciertos de sus actos sean calificados por ella misma o por otras como equivocados o tontos, o por el hecho de que los demás la acepten o condenen. Este autor, por lo tanto, subraya el valor del ser humano solo por el hecho de estar vivo y añade que aunque una existencia puede 
no ser del todo satisfactoria, siempre hay posibilidad de que lo sea.

La mejor estrategia para el manejo de problemas relacionados con el valor humano consiste en separar el problema o hecho del autor, de esta forma se reacciona ante el comportamiento apropiado o inapropiado, sin dar opiniones sobre el valor de la persona.

Los modelos humanísticos existenciales coinciden con esa filosofía positiva del ser humano. Como parte de sus principios básicos, de acuerdo con Feixas y Miró (1993), se señala la autorrealización, que se concibe como una tendencia inherente al organismo que lo impulsa hacia el crecimiento, la diferenciación y la búsqueda de sentido, entendido como el énfasis en el carácter intencional de la acción humana. Se sostiene que la persona no solo se mueve por motivaciones materiales, sino también por principios axiológicos, tales como la libertad, la justicia y la dignidad, que suponen el intento de trascender la propia existencia.

-Es un modelo de aprendizaje, no de enfermedad. Se espera que la persona aprenda a hacer lo adecuado $\mathrm{y}$ a sentir las emociones auténticas. Este enfoque considera que en la mayoría de los casos, la asignación de enfermedad mental está mal aplicada, ya que se trata (normalmente) de un desajuste de conducta o conductas inadecuadas, fruto del proceso de socialización.

El enfoque Conductual coincide con esta opinión. Corey (1989), señala que una premisa básica de la perspectiva conductual es que todas las conductas, cogniciones y emociones problemáticas han sido aprendidas y por lo tanto pueden ser modificadas con nuevos aprendizajes. Aunque este proceso de modificación frecuentemente es conocido como terapia, es más una experiencia educativa en la cual las personas se involucran en un proceso de enseñanzaaprendizaje.

Es un proceso educativo porque se enseña a las personas cómo mirar su propio proceso de aprendizaje e intentar formas más efectivas de modificar sus comportamientos, cogniciones y emociones.

Por otra parte, refiriéndose al enfoque Cognitivo, Garrido y García (1994) mencionan que este utiliza un modelo educativo, por cuanto el principio general que subyace es que las personas sufren porque desarrollan una forma errónea de dar significado al mundo, y lo que se busca mediante el proceso de orientación es enseñarles a desarrollar una nueva manera de ver la realidad. En última instancia, es un método de aprender a aprender de la realidad.

La Terapia Racional EmotivoConductual enseña a las personas a utilizar su modelo del ABCDE desde las primeras sesiones, por eso se considera que tiene una modalidad educativa como el Psicodrama, en el cual las personas aprenden y aplican las técnicas propias de esta terapia mediante el entrenamiento.

RefiriéndosealAnálisis Transaccional, Thomas (2000) subraya que en este enfoque se considera que las personas poseen el potencial para desenvolverse como seres autónomos y liberarse de los esquemas mentales y conductuales que limitan su crecimiento personal y su salud vital. Por lo tanto, es un enfoque para todas las personas y especialmente para aquellas que desean darle un sentido a su existencia y que consideran que sus pensamientos, conductas y formas de enfrentar las situaciones de la vida no son las más adecuadas.

Berne (1983) señala que:

En cuanto se refiere a la existencia real en el mundo, el Análisis transaccional comparte con el análisis existencial una elevada estima y un intenso interés por las cualidades personales de sinceridad, integridad, autonomía y autenticidad, lo mismo que por sus manifestaciones sociales más conmovedoras en el encuentro y la intimidad. (p. 342)

-Es sencillo. Emplea un vocabulario comprensible aún para personas en la etapa 
de la niñez. Berne (1983) indica que debido a la claridad de sus enunciados, basados en un material fácilmente accesible y a lo reducido de su vocabulario especializado, el Análisis Transaccional ofrece un marco de referencia de fácil aprendizaje para la clarificación. Es un enfoque racional y simple de cómo se estructura y funciona la personalidad, lo cual permite una mejor comprensión del comportamiento de las personas tanto en relación con ellas mismas como con las demás.

Thomas (2000) señala que el Análisis Transaccional es una teoría humanística que tiene como propósito central facilitar que la persona crezca y se desenvuelva plenamente al liberarla de ataduras y compromisos tales como los guiones psicológicos o argumentos de vida, juegos psicológicos y manipulaciones, enseñándole caminos hacia la autonomía, la intimidad, la honestidad y la autenticidad mediante el fortalecimiento de una posición existencial realista. Además, involucra paralelamente un modelo de aprendizaje, partiendo de que en general la conducta humana es el resultado de experiencias y aprendizajes del pasado, generalmente distorsionadas por presiones educacionales prejuiciadas e influencias negativas de otras personas y del entorno.

-Está basado en las necesidades de todo ser humano. Toma en cuenta necesidades tales como el afecto, el reconocimiento, la autoestima, la autoconfianza, la autonomía, el bienestar, la pertenencia y la aceptación social, dentro de un marco de armonía tanto intra como interpersonal. Asimismo, ofrece las bases necesarias para realizar cambios conductuales y hacer elecciones que favorezcan la autorrealización personal, relaciones humanas más adecuadas y satisfactorias y un mejoramiento en el estilo de vida de la persona. En el Existencialismo, uno de los propósitos fundamentales es ayudar a la persona a descubrir el significado de su existencia y mejorar sus relaciones con las demás. Por otra parte, en el enfoque Centrado en la
Persona, su creador, Carl Rogers (1961) señala que:

"Es un empeño evidente en toda vida orgánica y humana expandirse, extenderse, llegar a tener autonomía, desarrollarse, madurar, es la tendencia a expresar y activar todas las capacidades del organismo...” (p. 35).

En la terapia Gestalt, de acuerdo con Zinker 2000), se anima constantemente a las personas a intentar nuevos estilos de comportamiento para permitir la expresión de dimensiones de su personalidad que están adormecidas y para probar modos alternativos de conducta que les permita ampliar su capacidad de respuesta en el mundo.

-Es objetivo. Se basa en hechos cotidianos observables y registrables. Thomas (2000) señala que como modelo científico el Análisis Transaccional observa, coteja, evalúa, valora, actualiza, integra y modifica la conducta al separar el comportamiento en unidades simples y fácilmente identificables y comprensibles (análisis) y, al aplicar esos análisis a las relaciones interpersonales (transacciones). Opi y Beltrán (2005) agregan que este enfoque es predictivo, por cuanto la observación de las manifestaciones de conducta, junto con el conocimiento de la historia de vida de la persona, indica que si esta continúa aplicando el mismo "programa" mental, tenderá a obtener ciertos resultados predecibles y al ser predictivo, facilita la prevención.

-Es diagramable; es decir, emplea diagramas y esquemas simples mediante los cuales se pueden representar todo tipo de situaciones, lo cual le permite a la persona explicar o comprender fácilmente esta teoría. Esto favorece el autoconocimiento y permite de manera más fácil controlar comportamientos inadecuados o irracionales. De igual forma, en el enfoque Cognitivo se utilizan los gráficos, por ejemplo el gráfico de pastel, mediante el cual la persona puede identificar sus problemas y lo cambios que desea para su 
vida, determinar si existe un equilibrio entre las áreas de su existencia o las posibles causas de un evento determinado.

-El Análisis Transaccional facilita la integración de técnicas derivadas de otros enfoques, tales como la Gestalt, el Conductismo, el enfoque Cognitivo, la Bioenergética, la Terapia Racional Emotivo-Conductual, el enfoque Existencial, la Terapia Sistémica, entre otros, lo cual aumenta la capacidad de su uso en la práctica profesional y su aplicación tanto en la intervención individual como con grupos humanos en campos tales como el organizacional, el educativo y el familiar.

-Es contractual; es decir, se trabaja con base en objetivos establecidos con la persona orientada. El proceso se inicia con un contrato bilateral por cuanto se considera que el enfoque contractual protege la autodeterminación de la persona y le permite darse cuenta cuando ha logrado lo que se proponía. De igual forma ocurre en el enfoque Conductista, las primeras sesiones se dedican a establecer las metas personales que se desean alcanzar: conductas por cambiar y destrezas por aprender. También en el enfoque Cognitivo, durante la primera parte del proceso se ayuda a la persona a transformar las situaciones que presenta en objetivos de trabajo, los cuales se anotan en una hoja, con el título "lista de objetivos" y la fecha en que son formulados.

-Es igualitario; es decir, tanto la persona que facilita el proceso como la persona orientada se sitúan en el mismo nivel. De igual forma, en el enfoque Cognitivo se considera que se requiere de una sólida alianza terapéutica, muchos de los aspectos del proceso, tales como los tema que se van a trabajar durante las sesiones, la frecuencia de estas y las tareas por realizar, se deciden de forma conjunta. Feixas y Miró (1993) proponen un modelo de relación al que llaman de experto a experto, con el que amplían la propuesta de Rogers de una relación de persona a persona. En este modelo, los autores consideran que la persona orientada es experta en su mundo personal y quien orienta es una persona experta en relaciones humanas y en el funcionamiento de sistemas de construcción.

-El Análisis Transaccional facilita una autoexploración más profunda. De acuerdo con Naranjo (2004), el análisis estructural o de la personalidad que emplea este enfoque permite responder a las preguntas: ¿quién soy yo?, ¿por qué actúo de la forma en que lo hago? y ¿cómo llegué a ello? Se analizan pensamientos, sentimientos y comportamientos provenientes de los distintos estados emocionales del yo, se determinan los estados predominantes del yo y la dinámica interna entre ellos. El objetivo fundamental es establecer la comunicación más franca y auténtica posible entre los componentes afectivos e intelectuales de la personalidad.

En este enfoque se pretende que las personas fortalezcan su estado Adulto del Yo como directivo de la personalidad, para que puedan emanciparse y tomar sus propias decisiones en forma autónoma, sean capaces de evaluar antes de actuar y acepten la responsabilidad completa de sus pensamientos, sentimientos y conductas, y que realicen elecciones en forma consciente; es decir, que logren desarrollar un estado Adulto que funcione como árbitro entre los otros estados emocionales del yo.

El Análisis Transaccional también facilita que la persona pueda identificar sus posiciones psicológicas hacia sí misma, las otras personas y la vida y descubrir los mensajes recibidos y adoptados, probablemente desde la niñez, que sustentan esas percepciones.

Otro tipo de análisis que se emplea es el de los guiones del drama de la vida, los cuales están relacionados con decisiones y posiciones psicológicas mantenidas desde la infancia. Este análisis permite que la persona pueda entender cómo su guión o plan de vida se estructura con base en tres preguntas centrales que incluyen identidad y propósito: ¿quién soy yo?, ¿qué hago aquí? y ¿quiénes son los otros? 


\section{Tipos de análisis que conforman la teoría de Análisis Transaccional}

El Análisis Transaccional está constituido por cuatro tipos de análisis: el análisis estructural y funcional, mediante el cual se analiza la personalidad individual; el análisis transaccional, que facilita comprender lo que las personas hacen y dicen entre sí; el análisis de juegos psicológicos, que permite entender las transacciones ulteriores que conducen a una recompensa y el análisis de guiones, mediante el cual se estudian dramas específicos de la vida que las personas representan compulsivamente. A continuación se presentan de forma detallada cada uno de los cuatro tipos de análisis y otros temas relevantes de la teoría relacionados con estos, tales como las posiciones existenciales, las emociones y las caricias.

\section{Análisis estructural y funcional de la personalidad}

Es el primer tipo de análisis que propone esta teoría. Primero se hará referencia al análisis estructural y luego al análisis funcional de la personalidad para una mejor comprensión de estos.

\section{Análisis estructural de la personalidad}

Opi y Beltrán (2005) definen la personalidad como: "el modo habitual por el cual la persona piensa, siente, habla y actúa, para satisfacer sus necesidades de tipo personal, físico, psicológico y social" (p. 45). Por su parte, Santrock (2002) señala que: "la personalidad se refiere a razonamientos distintivos, emociones y conductas que caracterizan la forma en que un individuo se adapta al mundo" (p. 168).
En el desempeño de su labor como psicoterapeuta, Berne realizó múltiples observaciones, análisis y comprobaciones de diversas conductas (lenguaje, gestos, volumen y entonación de la voz, posiciones corporales) y estados de ánimo que sus pacientes asumían al exponerse a distintos estímulos. Estas manifestaciones conductuales y emocionales se presentaban claramente definidas. De este modo, en determinados momentos, la persona siente y se comporta como si fuera un niño de acuerdo con sus sentimientos e impulsos, en otros reproduce comportamientos adoptados de las figuras materna o paterna, por ejemplo estableciendo límites o protegiendo, y en otras situaciones muestra conductas que se esperan de una persona adulta y madura, racional analítica y realista. Berne reunió las características observadas en las personas en tres grandes grupos, a las que denominó Estados Emocionales del Yo, identificándolos como Padre, Adulto y Niño, las cuales no pueden ser consideradas como papeles, conceptos o abstracciones, sino realidades fenomenológicas. Berne (1961) define los estados del yo como "un sistema de emociones y pensamientos, acompañados de un conjunto afín de patrones de conducta” (p.24). Este mismo autor señala que uno de los objetivos fundamentales del Análisis Transaccional es: "establecer la comunicación más franca y auténtica posible entre los componentes afectivos e intelectuales de la personalidad". (p. 217).

Como puede observarse, en esta teoría cada vez que se hace referencia a los estados del Yo: Padre, Adulto y Niño, se escriben con mayúscula, para diferenciarlos de padres, adultos y niños reales. Cada uno de esos estados posee sus propios contenidos y sus propias características.

El estado Padre del yo. Este estado contiene las grabaciones que se realizaron durante la infancia provenientes del contexto, de patrones y valores socioculturales y de la incorporación de mensajes enviados por las figuras parentales y otras figuras significativas. Esta parte de la personalidad 
transmite, por ejemplo, normas, prohibiciones, críticas, prejuicios y estereotipos. Puede realizar generalizaciones o hacer argumentos poco reflexivos. Tiende a dar órdenes, imponerse y dominar, pero también puede mostrar conductas mediante las cuales protege, aconseja, escucha, brinda apoyo o se solidariza y en algunos casos puede llegar a la sobreprotección.

El estado Adulto del yo. Es la parte racional de la personalidad. Se interesa por obtener datos de la realidad, analizarlos y someterlos a prueba. Se esfuerza por diferenciar la fantasía de la realidad. Establece y trata de lograr objetivos y metas realistas. Tiene una visión clara de sus valores y actúa en concordancia con estos. Busca, solicita y brinda información. Por sus características, este estado resulta de gran importancia para la toma de decisiones. Senlle (1991) menciona otras características de este estado, tales como: mostrar una conducta coherente, buscar soluciones adecuadas a los problemas, librarse de patrones ilógicos (provenientes del Padre) o de anhelos (provenientes del Niño), no responsabiliza a otras personas de sus problemas y no pretende dominar sino colaborar. Pregunta, investiga, razona y escucha.

El estado Niño del yo. En este estado se encuentra todo el componente emocional de la persona. Esta parte del yo puede dejarse llevar por la emotividad, ser impulsiva y egocéntrica, reclamar afecto, exigir que se le tome en cuenta, tener temor de actuar o de sentirse solo o vivir la vida alegremente, evadiendo responsabilidades. Sueña, fantasea, miente y manipula, pero también es la parte que siente (toda la gama de emociones), intuye y crea.

Es importante mencionar que el empleo de los tres estados emocionales del yo es necesario para el logro de un equilibrio personal, e independientemente de la edad, todas las personas poseen, en algún grado, cada uno de ellos. No obstante, a veces se presentan algunas situaciones especiales, que en términos de Análisis Transaccional se le conoce como patologías estructurales de la personalidad.

\section{Patologías estructurales de la personalidad}

Entre estas se pueden mencionar las contaminaciones, los estados del yo exclusivos y los estados del yo excluidos, de acuerdo con autores como Opi y Beltrán (2005), Thomas (2000) y James y Jongeward (1976).

La contaminación se considera como la intromisión de un estado emocional en otro. Así por ejemplo, cuando el Adulto es contaminado por el Padre, admite como ciertos juicios infundados, tales como los prejuicios. En este caso, pareciera que la persona se expresa mediante su Adulto, cuando en realidad lo hace desde su Padre. Por otra parte, cuando el Adulto admite como verdades distorsiones de la realidad, racionalizándolas, es porque ha sido contaminado por su Niño. Ejemplos claros de esta contaminación son las supersticiones, las fantasías y en caso extremo las alucinaciones. Puede darse asimismo una doble contaminación, cuando el Adulto queda a expensas de los estados Padre y Niño, justificando de esta forma sus prejuicios y supersticiones. En distinta medida todas las personas experimentan contaminaciones en ciertos momentos de su vida.

En cuanto a los estados exclusivos, algunas personas permanecen funcionando casi exclusivamente desde un solo estado emocional de su yo y los otros dos estados se mantienen más o menos excluidos. Como ejemplos del Padre exclusivo podrían mencionarse al dictador o al moralizador; como Adulto exclusivo a la persona excesivamente metódica o insensible y como Niño exclusivo a la persona eternamente bromista, incapaz de tomarse nada en serio.

Por otra parte, están los estados excluidos del yo, en este caso funcionan dos estados del yo y un tercero es prácticamente anulado. Por ejemplo, si el estado Padre es excluido, hay una ausencia de normas, límites y responsabilidades. Si el Adulto es excluido, hay una pérdida de contacto con la realidad, no se razona y probablemente no se tomen decisiones de forma adecuada. 
Si el excluido es el Niño, entonces se reprimen las emociones, las necesidades, los deseos y el placer.

\section{Análisis funcional de la personalidad}

Los tres estados del yo: Padre, Adulto y Niño conforman la estructura total de la personalidad; no obstante, existen diferencias en el actuar y en el sentir, aún dentro de cada uno de esos estados, lo que condujo a una subdivisión más precisa y compleja que permite una mejor comprensión del comportamiento y funcionamiento personal. A esta nueva representación de la personalidad se le conoce como Estructura Funcional.

En esta Estructura Funcional, el estado Padre del yo tiene dos formas de manifestación importantes, conocidas como el Padre Crítico-Normativo y el Padre Protector-Nutricio. El estado Adulto del yo no tiene ninguna subdivisión, mientras que en el estado Niño del yo pueden distinguirse cuatro formas principales de manifestación, denominadas Niño Natural-Libre, Niño Adaptado-Sumiso, Niño Adaptado Rebelde y Niño Creativo-Pequeño Profesor.

Sobre este tema, autores como Opi y Beltrán (2005) y Senlle (1991) ofrecen una amplia explicación que se resume a continuación.

Padre Crítico-Normativo. En este estado la persona puede actuar señalando límites o normas de comportamiento que pretenden básicamente preservar la vida o la dignidad de otras personas (Padre Normativo), pero también puede manifestar críticas destructivas, desvalorizar, emitir juicios y exhibir conductas agresivas o represivas (Padre Crítico).

Padre Protector Nutricio. La expresión de una conducta de protección puede ser positiva, no obstante si llega al extremo de la sobreprotección se convierte en insana, por cuanto impide el desarrollo del Adulto de otras personas, provocando relaciones de dependencia y por ende pérdida de autonomía. Este estado es positivo cuando manifiesta comportamientos de afecto, apoyo, protección y seguridad, cuando son requeridos por otras personas; se respeta la libertad y hay tolerancia hacia las creencias y opiniones de las demás. Es negativo cuando, como se mencionó, se sobreprotege, se realizan trabajos o se asumen responsabilidades que no le corresponden y la persona se olvida de sí misma, de sus deseos y necesidades propias; es decir, solo piensa y actúa en función de otras, dejando de lado su propia existencia.

Adulto. A pesar de que no tiene subdivisiones, también puede tener aspectos positivos y negativos. Es positivo cuando establece objetivos y metas concretas, reúne la información necesaria para tomar decisiones y analiza las situaciones y comportamientos de forma objetiva. Se transforma en negativo cuando para lograr sus propósitos irrespeta los derechos de otra personas sin tomar en cuenta sus sentimientos, es tan racional que no permite la expresión de sus propias emociones, se detiene tanto en reunir información que cuando por fin decide ya es tarde, o se dedica a analizar a otras personas para justificarse a sí misma.

Niño Adaptado Sumiso-Rebelde. Entre las actitudes positivas de este estado se puede mencionar los comportamientos que indican disciplina, el acatamiento de normas y el respeto por otras personas, que benefician la sana convivencia interpersonal. En el aspecto negativo se encuentran las conductas de confusión, retraimiento, negativa a actuar por temor a la crítica, a la represión o sanción, o bien manifestarse desafiante y hostil y con conductas desproporcionadas ante una situación determinada. Sin embargo, el Niño Rebelde puede presentar comportamientos positivos, por ejemplo aquellos que le permiten proteger la vida frente a actos como la agresión o la persecución, o cuando no acepta normas impuestas duramente o que son injustas.

Niño Natural-Libre. En su aspecto positivo, este estado del yo se manifiesta de forma natural y espontánea, siente y vive las emociones auténticas de manera plena, gusta disfrutar la alegría de vivir 
compartiendo con otras personas. Por otra parte, también puede presentar conductas inadecuadas y egocéntricas o disfruta y se divierte pero sin tomar en cuenta lo que desean o sienten las y los demás.

Niño Creativo-Pequeño Profesor. En este estado se encuentra el origen y hay un gran potencial para la creatividad, por ejemplo artística o científica y para la originalidad. Contiene aspectos como la curiosidad, el deseo de aprender, el empleo de la intuición y la sensibilidad. Es el estado que rompe la rutina. En su manifestación negativa, puede presentar conductas manipuladoras, egoísmo, inventar situaciones falsas o mentiras.

Todas las personas emplean en distinta medida los estados del yo mencionados, lo importante es observar y tratar de controlar aquellas manifestaciones nocivas y emplear cada estado según la situación que se esté viviendo; es decir, utilizar cada estado en el momento adecuado y oportuno.

\section{Posiciones existenciales}

Todas las personas poseen una percepción respecto de sí mismas, de las otras personas y de la vida. A estas percepciones o conceptos se les conoce como posturas o posiciones existenciales. Estas se originan a partir de la historia de vida y de los mensajes que la persona recibió desde su infancia provenientes de figuras significativas; de esta manera, las creencias sobre sí, las y los otros y la vida quedan grabadas formando mitos, por cuanto pueden no corresponder a realidades, que llevan a la persona a actuar de determinadas formas para confirmarlos. La posición elegida inconscientemente durante la niñez es la básica; es decir, la persona se encuentra en ella la mayor parte del tiempo.

Existen cuatro patrones básicos de posiciones existenciales: Yo estoy bien, tú estás bien; Yo estoy bien, tú estás mal; Yo estoy mal, tú estás bien y Yo estoy mal, tú estás mal. Senlle (1991) y Naranjo (2004) las explican de la siguiente manera:

Yo estoy bien, tú estás bien. En esta posición se encuentran aquellas personas que recibieron durante su niñez afecto, caricias, mensajes positivos, atención y cuidados por parte de sus progenitores y otras figuras significativas. Las personas que adoptan esta posición pueden resolver sus problemas de forma creativa y constructiva, son realistas y consideran valiosas a las otras personas. Es la posición de una personalidad saludable.

Yo estoy bien, tu estas mal. Proyectiva. Las personas que han sido agredidas o denigradas pueden llegar a pensar que ellas están mal. Es la posición de quienes se sienten víctimas o perseguidas. Tienden a seguir culpando a las otras personas de sus desdichas y fracasos. A medida que pasa el tiempo pueden empezar a devolver el odio acumulado, a agredir antes de ser agredidas. Es una posición adoptada con frecuencia por criminales y delincuentes, que se transforma en una conducta paranoide y que en casos extremos puede llevar al homicidio.

Yo estoy mal, tú estás bien. Introyectiva. Es la posición adoptada por las personas que recibieron constantemente mensajes negativos, lo que pudo llevarlas a la conclusión de que son personas malas y que las otras son buenas y con base en esto construyen su autoestima. Es la posición de quienes se sienten menos o impotentes al compararse con otras personas. Generalmente se aíslan, sufren de depresión y en casos extremos pueden llegar al suicidio.

Yo estoy mal, tú estás mal. Inutilidad. Cuando durante la infancia las personas han sido abandonadas o reciben siempre mensajes que las conducen a la inseguridad y a la desconfianza, aunado a una ausencia de reconocimientos o afecto, pueden llegar a la conclusión de que no están bien, pero tampoco las otras personas lo están. Es la posición de quienes pierden interés en seguir viviendo y en 
casos graves y extremos pueden cometer homicidio o suicidio o ambas.

En cuanto a la posición ante la vida, la persona que adopta la primera posición piensa que vale la pena vivir la vida. Si adopta la segunda, considera que la vida de las otras personas apenas tiene valor. En la tercera posición, cree que su vida no vale la pena y en la cuarta, piensa que la vida no vale nada, ni la suya ni la de las demás.

Pese a lo mencionado anteriormente, es importante decir que las posiciones existenciales pueden fluctuar dentro de ciertos límites, dependiendo de las situaciones y experiencias vitales que la persona vaya teniendo y del tipo y calidad de las relaciones que establezca con otras personas. Por otra parte, posiciones existenciales negativas muy arraigas se pueden modificar a partir de un buen autoanálisis realizado con ayuda de un especialista.

\section{Las emociones en el Análisis Transaccional}

De acuerdo con Camino y Coca (2006) la emoción es una forma determinada de aprehender el mundo e incluso un intento por transformarlo, por ejemplo cuando una persona experimenta temor y realiza una acción para eliminar el objeto temido. Señalan estos autores que en el área de la afectividad se pueden distinguir las emociones, considerándolas un estado de ánimo intenso, de corta duración y acompañadas de manifestaciones psicosomáticas como taquicardia o sudoración, de los sentimientos, entendiéndolos como un estado de ánimo más tranquilo y perdurable y sin reacciones psicosomáticas manifiestas.

De acuerdo con los autores arriba mencionados, las emociones básicas son cinco: el amor, la alegría, la rabia, la tristeza y el miedo. El Análisis transaccional subraya además la diferencia con las emociones no auténticas, entre ellas la ansiedad y la melancolía. Se señala, por ejemplo, que los celos son un amor contaminado de miedo y que la envidia es tristeza contaminada de rabia. Por otra parte, lo que determina la percepción emocional de la persona es la manera en que fueron condicionadas o adaptadas las emociones durante las etapas tempranas del desarrollo.

Senlle (1991) coincide con los autores mencionados. Indica que las emociones naturales o apropiadas son sanas y auténticas. Los emociones falsas o inapropiadas en realidad son sustitutas de otras naturales que por alguna razón no se pudieron expresar y muchas de ellas fueron aprendidas durante la infancia de emociones desproporcionadas expresadas por figuras significativas. De esta forma se puede encontrar la falsa rabia, la falsa alegría, la falsa tristeza, el falso amor, el falso miedo y otras como la depresión, la frustración, la angustia, la impotencia, la inadecuación, la inseguridad y la culpa, para mencionar algunas. Una de las razones por la que las personas aprenden esas emociones es porque de alguna manera le han permitido manipular a otras.

Las emociones falsas son causa de muchos problemas y perturbaciones tanto psicológicas como psicosomáticas y sociales. La persona se siente mal y no es feliz, con el tiempo adopta una actitud de fracaso, impotencia e inadecuación, que la lleva a conformarse con un yo soy así. Otras personas sufren enfermedades como alergias, jaquecas, malestares en el estómago, originadas por el tipo de emociones que con frecuencia experimentan.

El desarrollo tanto físico como emocional sano implica tomar conciencia de las emociones y los sentimientos que se experimentan y encontrar una forma adecuada de manifestarlos.

Oller (2005) presenta una perspectiva muy interesante de la relación entre las emociones y los estados del yo. Explica que en el Análisis Transaccional se distinguen tres tipos de emociones que pueden manifestarse: las naturales, las elásticas y las parásitas. Las naturales son manifestaciones funcionales apropiadas a la situación por su 
naturaleza, intensidad y duración. Las elásticas son manifestaciones que aparentan ser apropiadas por su naturaleza a la situación, pero son exageradas por su intensidad y duración. En cuanto a las parásitas, son manifestaciones inapropiadas por su naturaleza a la situación y además son exageradas por su intensidad y duración. Según este esquema, por ejemplo, la tristeza que expresa una persona puede ser una tristeza natural del Adulto, una tristeza elástica del Niño o una tristeza parásita de este aprendida en la infancia, o manifestada por el Padre y que se repite copiada de una figura parental del pasado.

En los tres estados del yo las emociones que se viven son naturales si se trata de las emociones básicas: el afecto, el miedo, el enfado, la tristeza, la alegría y la tranquilidad, considerada esta última como el estado base de homeostasis emocional.

\section{Las caricias dentro del Análisis Transaccional}

En Análisis Transaccional el tema de las caricias ocupa un lugar central por cuanto se considera que todo ser humano necesita de estas para su supervivencia, tanto biológica como psicológica. Opi y Beltrán (2005) señalan que:

A partir de esta premisa, se debe considerar que cualquier contacto, acción o mensaje tanto físico como verbal o simbólico con el que una persona transmita a otra algún tipo de reconocimiento, tanto positivo como negativo, es lo que se llama caricia. La caricia es, pues, la unidad de reconocimiento social. (p. 188).

Berne (1988) integró las leyes de la biología humana con las normas de interacción social en su famosa frase metafórica: "Las personas necesitan caricias, y si no las consiguen, su espina dorsal se les secará" (p.14-15)

Los autores mencionados y Senlle (1991) se refieren a la clasificación de las caricias. Estas se clasifican en positivas, negativas, mixtas, condicionales e incondicionales. Las caricias positivas producen emociones o sensaciones agradables, invitan a sentirse bien y favorecen la autoestima. Se manifiestan generalmente mediante el afecto y el aprecio (una sonrisa, un abrazo, un te quiero). Las caricias negativas producen emociones desagradables, hacen que la persona se sienta mal, le causan dolor o daño moral o físico y reducen su autoestima (decirle a alguien que todo lo hace mal, golpear a un hijo). Las caricias mixtas son una mezcla de caricias positivas y negativas, son caricias falsas por cuanto tienen un contenido de desvalorización (decirle a alguien que el trabajo le ha quedado bien, quién lo iba a creer). Las caricias condicionales son las que se dan por conductas objetivas, sean positivas o negativas (decirle a alguien que ha hecho un buen informe o el informe que presentó no sirve para nada). Las caricias incondicionales son las que se ofrecen por el simple hecho de ser y no porque la persona haya logrado o realizado nada especial (decirle a alguien: ¡qué alegría me da verte!).

Refiriéndose a las caricias positivas, Giardino (2010) menciona que las personas pueden aprender a dar y recibir caricias libremente. Existen muchos tipos de caricias que gustan a diferentes personas y todas tienen sus deseos especiales; de todas formas, ellas necesitan y merecen ser acariciadas y si solicitan caricias pueden encontrar a alguien que tenga justo las que desea y que esté dispuesta a darlas.

Steiner (1997), quien trabajó con Berne, señala que las caricias son una fuente poderosa de estímulos y ricas en información. Estas se obtienen en la intimidad, en el trabajo, en los pasatiempos y en el juego. Agrega que: "A estas ideas yo añadí el concepto de "economía de caricias" que establece que debido a una serie de reglas que limitan los intercambios de caricias positivas de las personas, éstas sufren hambruna crónica de caricias" (p. 8). La Ley de la Economía de caricias se rige por 
las siguientes reglas: no dé las caricias que quiera dar; no pida las caricias que quiere; no acepte las caricias que quiera; no rechace las caricias que no quiere y no se dé caricias a sí mismo. El Padre Crítico refuerza esas reglas a partir de una amplia base social.

El mismo Steiner (1980) se refiere a otra ley, La Ley de Abundancia de Caricias, la cual se rige por las siguientes reglas: dé abundantes caricias positivas; acepte las caricias positivas que merezca; pida las caricias positivas que necesite; dese caricias positivas; no acepte las caricias no que desea recibir y no intercambie caricias negativas o inadecuadas.

\section{Análisis Transaccional y Comunicación Humana}

Es el segundo análisis que Eric Berne propone en esta teoría. De acuerdo con Valbuena (2004), el propósito central de este análisis es el control social; es decir, que en el Adulto se deposite el poder ejecutivo, de modo que no se manipule a otras personas y a la vez no se permita que estas lo manipulen, impidiéndole emplear su razón e intuición.

Berne (1988) llama transacción a la unidad de las relaciones sociales:

Si una o dos personas se encuentran en un grupo social, tarde o temprano alguna de ellas hablará o dará alguna señal de reconocimiento de las otras. Esto se llama estímulo transaccional. Entonces, otra persona dirá o hará algo que está de algún modo relacionado con este estímulo, y eso se llama respuesta transaccional. Basta un sencillo análisis de la transacción para diagnosticar qué Estado del Ego cumplió con el estímulo y cuál ejecutó la respuesta (p.37).

Para realizar el análisis de una transacción, explica Valbuena (2004), deben seguirse los siguientes pasos: primero, averiguar cuál estado del yo está dirigiendo el estímulo transaccional; segundo, identificar cuál estado del yo está activado en la respuesta transaccional; tercero, visualizar, mediante diagramas, la dirección del estímulo y de la respuesta; cuarto, denominar el carácter de la transacción y quinto, encontrar el significado esencial de las transacciones.

Todas las transacciones entre las personas se pueden clasificar como complementarias, cruzadas o ulteriores.

Transacciones complementarias. De acuerdo con Muriel y Jongeward en Naranjo (2004), una transacción es complementaria cuando el mensaje enviado por un estado específico del yo recibe, desde un estado determinado del yo de la otra persona, la respuesta prevista. Este tipo de transacción puede ocurrir entre dos estados del yo: Padre-Padre, Niño-Niño, Adulto-Adulto, Padre-Niño, Niño-Padre, Niño-Adulto, Adulto-Niño, Adulto-Padre, Padre-Adulto.

Transacciones cruzadas. Estas ocurren cuando la respuesta al estímulo es inesperada, se activa un estado inapropiado del yo y como resultado las personas optan por retirarse o cambiar de conversación. Generalmente, originan situaciones dolorosas entre las personas, pues al no recibir la respuesta esperada, la persona se siente frustrada. Por ejemplo, una persona puede dirigirse desde su Adulto al Adulto de la otra persona, pero esta le responde desde su Padre Crítico.

Transacciones ulteriores. Estas son las más complejas. Se diferencian de las transacciones complementarias y de las cruzadas porque siempre participan más de dos estados del yo. Por ejemplo, aparentemente desde el Adulto: "¿Dónde has escondido el abrelatas?" (el estímulo parece provenir del Adulto por cuanto pide información objetiva, pero en la palabra "escondido" hay una comunicación ulterior), este mensaje viene desde el Padre crítico: “iSi pudiera encontrar por una sola vez algo que esté en su sitio!" (la marcha de la transacción depende del estado del yo desde el que se responda), respuesta desde un Adulto con humor: "Lo escondí al lado de las cucharas." (la respuesta es complementaria porque da la información solicitada), respuesta desde el Padre 
Crítico: “¿Qué te pasa, estás ciego?, nunca encuentras nada"; desde el Niño (haciendo pucheros) "Tú siempre me criticas".

Valbuena (2004) explica que las transacciones Padre-Crítico, Padre-Crítico se utilizan para intercambiar indagaciones basadas en prejuicios, no en hechos. Las transacciones Adulto-Adulto son propias de colaboradores y tienen el carácter de resolución de problemas. También pueden ser de respeto, las personas se comprometen y no buscan excusas para no cumplir sus compromisos. Las transacciones Niño-Niño tienen varios significados: juego, intimidad, amor y se consideran las más durables de la vida humana. Cuando las personas se comunican de forma complementaria e igualitaria, es señal de compañerismo. Por ejemplo, las personas pueden intercambiar prejuicios Paternales, brindarse consejos Adultos o divertirse juntas como Niños. Si las personas continúan conociéndose mutuamente, pueden llegar a la amistad; mediante esta intercambian información y sentimientos y no se asumen posiciones de superioridad.

Por otra parte, en las transacciones Niño-Padre suele surgir la admiración y en las de Padre-Niño, el afecto. En las transacciones Padre-Adulto, una persona apoya a otra para que tome una decisión oportuna y en las de Adulto-Padre, una persona desea mantener una posición asertiva $\mathrm{y}$ la otra acepta. Las transacciones NiñoAdulto evidencian una solicitud de ayuda y las de Adulto-Niño se consideran propias de personas que aconsejan y que enseñan.

Senlle (1991) menciona que quien habla como Padre busca Niños que le respondan aceptando lo que dice o pretende, o bien que le permitan protegerlos. Se relaciona bien con personas que se expresan desde su Niño Sumiso. Quien habla como Adulto pretende comunicarse de forma clara y obtener información precisa, no quiere críticas (provenientes del Padre Crítico), ni protección (proveniente del Padre -Protector) ni lamentos (provenientes del Niño). Quien habla como Niño-Libre puede mantener buenas relaciones en momentos de ocio o de juego; no obstante, en el trabajo, si desea pasarla bien, puede tener problemas con personas que están en su Adulto o en el Padre. Quien habla como Niño-Rebelde compite con otras personas que también están en su Niño o discute con las que están en su Adulto o en su Padre. Si habla como Niño Sumiso, puede relacionarse bien con las personas que están en su estado Padre-Protector.

Opi y Beltrán (2005) señalan que:

\begin{abstract}
"A través de las Transacciones los seres humanos informamos al mundo, consciente o inconscientemente, de aquello que pensamos, sentimos, decimos y hacemos" (p.119).
\end{abstract}

\section{Análisis de los juegos psicológicos}

Es el tercer análisis de la teoría de Análisis Transaccional. Se entiende por juego psicológico una serie de transacciones que tienen un mensaje oculto o ulterior y que concluyen con una recompensa emocional, la cual es una caricia perjudicial que conduce a las personas a las posiciones existenciales "yo estoy mal" o "tú estás mal". Los juegos impiden las relaciones íntimas y sinceras entre los jugadores.

De acuerdo con Martorell (2000) las principales características de los juegos son: a) se repiten constantemente; b) ocurren siempre de un modo similar y c), al final todas las personas que intervienen en el juego reciben su recompensa, que es sentirse mal de alguna manera.

Senlle (1991) señala que para jugar los juegos psicológicos, las personas eligen un determinado papel. Estos roles o papeles básicos son: Perseguidor, Salvador y Víctima y dentro del juego los jugadores los intercambian con frecuencia. A estos roles se les conoce como el Triángulo Dramático. Martorell (2000) explica que: $<<$ El Perseguidor necesita que le teman, e "invita" a sentir temor. El Salvador necesita 
que le necesiten, e "invita" a sentirse inútil y agradecido a él. La Víctima necesita que le humillen o que lo venzan, e "invita" a sentir culpa" >> (p. 42). Es importante aclarar que estos papeles psicológicos son actuados y falsos, por lo que se escriben con mayúscula para diferenciarlos de situaciones reales; por ejemplo, un policía es un perseguidor real de un delincuente, una persona que salva a otra de ahogarse es un salvador real y un niño que es agredido es una víctima auténtica.

Durante la infancia se aprenden los juegos. Así, una niña o un niño puede darse cuenta que obtiene lo que desea haciéndose la víctima, poniendo en mal a sus compañeros (persiguiendo) o salvando a sus hermanos. Estos papeles se copian de figuras significativas y posteriormente la persona irá por la vida participando en juegos psicológicos que le permitan poner en práctica el proceder correspondiente al papel o papeles aprendidos.

Según esta teoría, todos los juegos responden a una fórmula que siempre se repite de igual manera: cebo, flaqueza, respuesta, cambio y beneficio. El cebo es el estímulo que envía la primera persona (por ejemplo pedir consejos), el cual lleva algo oculto que tiene como propósito enganchar (en lenguaje transaccional) alguna característica sensible de la otra persona. La flaqueza es la parte débil de esa otra persona que responde al cebo (siente que tiene que dar consejos a otras para que resuelvan sus problemas). La respuesta es la acción o las frases con las que la segunda persona entra en el juego (los consejos que brinda). El cambio es cuando la persona que inició el juego cambia su actitud sorprendiendo al segundo jugador (sus consejos no me sirvieron de nada), quien generalmente también cambia de actitud (yo solo quería ayudar). El beneficio se da cuando ambas personas terminan sintiéndose mal. Pasado algún tiempo el juego se vuelve a repetir con los mismos resultados. Si ninguna de las dos personas se retira, el juego se repetirá indefinidamente.
Se considera que existen muchas razones para jugar juegos psicológicos, entre las más importantes están: lograr la atención de otras personas; sentirse mal para que le protejan; obtener caricias aunque sean negativas, pues finalmente constituyen una forma de reconocimiento; fortalecer posiciones existenciales (por ejemplo sentirse defraudado para sostener su posición de que no se puede confiar en nadie porque "están mal"); controlar a otras personas y evitar situaciones que se temen, como la intimidad, por cuanto los juegos impiden las relaciones abiertas y sinceras.

Los juegos se vinculan con conductas dependientes o simbióticas. Lo ideal de las relaciones entre las personas es que cada una de ellas conserve su autonomía, la capacidad y libertad de tomar sus propias decisiones según sus deseos y propósitos y que de esa relación se obtenga un producto positivo.

Muchos autores transaccionalistas se refieren a los juegos psicológicos desde el mismo Berne (1988) en su obra Juegos en que participamos. Lo mismo hacen otros seguidores, a partir de Psicología de las relaciones humanas, autores como James y Jongeward (1976), Jongeward (1980) y Coca (2004) para mencionar algunos. A continuación se hace referencia a algunos de estos juegos, a manera de ejemplo.

Imperfección. Lo juegan personas demasiado detallistas, que se fijan en aspectos pequeños e insignificantes para buscar problemas con otras. Generalmente no toman en cuenta la situación total, pues están muy ocupados con las trivialidades. Las cosas nunca están bien, siempre existe un defecto. Su recompensa es un falso sentido de superioridad que experimenta cuando la persona a la que critica (la Víctima) se siente molesta o enojada.

Pata de palo. En este, el jugador utiliza con éxito una situación desafortunada, real o imaginaria para evitar actuar o asumir responsabilidades. Siempre tiene un pretexto que utiliza para manipular a otras personas y lograr que estas asuman 
sus trabajos. El mensaje que envía desde su posición de Víctima es: qué se puede esperar de una persona como yo (con una pata de palo).

Golpéame. Estos jugadores provocan a otras personas para que los humillen y lo logran empleando una variedad de formas; por ejemplo, realizando trabajos mal hechos, entregándolos después de la fecha indicada o desatendiendo indicaciones sobre cómo realizar una tarea. Buscan ser acariciados negativamente, pues es probable que sea el tipo de caricias que han aprendido a recibir o esperar.

Ya te pesqué. Este jugador acostumbra poner trampas, como pedir cosas que son imposibles de lograr, dar indicaciones ambiguas de cómo realizar un trabajo o establecer normas confusas. Cuando la otra persona no cumple con lo que desea disfruta sus propias explosiones de ira y la recompensa de un sentimiento justificado de Perseguidor. Es probable que la Víctima esté jugando a "golpéame". En este caso, sus papeles se complementan perfectamente.

Perdóname. El propósito del jugador de golpéame es ser humillado y aunque el jugador de perdóname realiza las mismas cosas, su objetivo es ser perdonado para asegurarse de que es aceptado, independientemente de lo que haga. De esta forma, cada vez que comete un error, que obviamente son muy frecuentes, pide perdón una y otra vez hasta lograr que la otra persona le diga que no se preocupe, que un error lo comete cualquiera.

Si no fuera por ti. La persona que utiliza este juego generalmente se siente incapaz o inadecuada, pero en lugar de reconocer estos sentimientos culpa a otra persona de su situación. La recompensa la obtiene cuando llega a creerse justa y logra que la otra se sienta mal y culpable.

Sí, pero... El jugador inicia el juego solicitando un consejo para resolver una situación, cuando las otras personas ofrecen sus consejos, el jugador rechaza todas las sugerencias con un "sí, pero" y da algunas razones de por qué las sugerencias no son válidas. El juego termina cuando las otras personas se cansan o no tienen más argumentos y él obtiene su recompensa manteniendo su posición: "nadie me va a decir a mí lo que debo hacer".

Vamos a pelear tú y él o ella. En este juego una persona provoca un problema entre otras dos para mantener su posición: "la gente es tonta". El jugador inicia el juego diciéndole a otra, por ejemplo: "Carlos, sabes que te aprecio mucho y por eso creo que debo decirte que Juan ha expresado cosas muy negativas de ti". El jugador logra su recompensa cuando las personas a quienes involucró se pelean.

Cazador de osos. Este jugador envía mensajes que son trampas: "confía en mí", aparenta ser una buena persona, buena escucha y hace promesas, las cuales, por supuesto, no son reales. Este jugador disfruta del control que posee sobre la otra persona para dejarla impotente.

Alboroto. Consiste en provocar a otra persona con un comportamiento verbal o no verbal que lleva a un enfrentamiento de palabras hirientes y finalmente a una retirada hostil de ambas partes. Con esto se logra la recompensa que es evitar la intimidad o enfrentar una situación de forma racional y sincera. Este juego se practica mucho entre parejas y entre padres e hijos.

\section{Dejar de jugar juegos psicológicos}

Senlle (1991) menciona cuatro pasos para dejar de participar en juegos psicológicos: el primer paso es darse cuenta de situaciones que suceden de forma repetida y que terminan por hacer sentir mal a la persona; es decir, identificar el juego y sus partes (cebo-flaqueza-respuesta- cambio y beneficio). El segundo paso es determinar el papel que se está desempeñando en el juego (Perseguidor- Salvador o Víctima). El tercer paso es identificar el mito que sobre sí se confirma en el juego (lo que la 
persona cree que es, su auto-percepción). Y el cuarto paso consiste en dejar de buscar caricias negativas mediante los juegos y, en cambio, buscar caricias positivas de formas más adecuadas.

Por otra parte Jongeward (1980) ofrece las siguientes sugerencias:

- Dar una respuesta inesperada. Debido a que los juegos implican situaciones repetitivas, son predecibles, esto permite dar una respuesta inesperada desde la primera acción; por ejemplo, si la persona se presenta como Víctima buscando que se le solucione un problema, en lugar de darle la solución se le puede decir: "¿qué piensa hacer al respecto?”.

- Dejar de humillar. Una característica común de muchos juegos es la humillación. Al participar en un juego se reciben o se dan caricias negativas, por lo tanto, si se reduce la frecuencia de darlas o se niega a recibirlas, automáticamente se reduce la participación en juegos.

-Aumentar la confianza en sí misma o en sí mismo. En los juegos la posición psicológica común es estoy mal, o sea, la autoestima está disminuida, si se aumenta esta se fortalece el sentimiento de "estoy bien" y por ende la autovaloración, que permite a la persona aceptar que merece el éxito.

-Dejar de actuar papeles falsos. De esta forma, si ya no se juega el papel de Víctima se deja de atraer Perseguidores y Salvadores, si se abandona el papel de Salvador, ya no se atraen jugadores de Víctimas y si se deja el papel de Perseguidor, buscar Víctimas ya no es necesario.

- Dar y recibir un mayor número de caricias positivas. Si en los juegos se otorgan caricias negativas, una forma de detenerlos es invirtiendo más tiempo en dar y recibir caricias positivas.

- Correr el riesgo de actuar con franqueza. Otra forma de detener los juegos es arriesgándose a ser sinceros, a fin de realizar transacciones más abiertas y honestas con las otras personas.

\section{Análisis de guiones o dramas de la vida}

El análisis de los guiones o dramas de la vida corresponde al cuarto análisis de Análisis Transaccional. Autores de este enfoque, tales como Martorell (2000), Senlle (1991), Steiner (1991), entre otros, se refieren ampliamente al tema de los guiones y otros aspectos relacionados con estos. A continuación se hace referencia, siguiendo a estos autores, de lo más relevante.

Para entender el guión de vida de una persona, muchas veces se hace necesario ir muy lejos, incluso antes de su nacimiento, por cuanto desde antes de su llegada comúnmente hay una familia que le está esperando, en especial el padre y la madre, cuya vida, en alguna medida, se va a modificar a causa de su llegada. Lo anterior significa que ya existen algunos sentimientos; por ejemplo, puede ser una hija o un hijo querido y esperado o no por uno o ambos progenitores, se puede tener la expectativa de que venga a salvar una relación de pareja, para que llene un vacío o incluso para que dé significado a la existencia. Pero de igual forma puede generar temor de no saber si se tiene la capacidad para atenderla o atenderlo, de que le robe el amor de su pareja, que trunque o aplace una meta, como el logro de una carrera profesional. Es decir, desde antes de nacer se le está otorgando una función, ya existen expectativas sobre esta persona y su vida, lo que genera unos determinados sentimientos, todo lo cual será captado posteriormente por la niña o el niño mediante los mensajes que se le envíen, el tipo de caricias que se le brinden o en el peor de los casos, la ausencia de estas.

Los aspectos más importantes de la situación de una persona cuando llega a la familia se pude decir que son: su total necesidad de los cuidados tanto físicos como emocionales; la expresión de sus impulsos naturales a medida que se desarrolla y las ideas, expectativas y sentimientos de 
los progenitores sobre ella; es decir, cómo encaja, qué se le pide, qué puede o debe ser o hacer desde la perspectiva de los guiones de sus progenitores. Se dice entonces que la niña o el niño se encuentra en una encrucijada: puede seguir sus propias tendencias pero se arriesga a perder la aceptación de sus padres, de quienes depende para su sobrevivencia, o se asegura su aceptación pero a costa de la represión de sus tendencias naturales.

Se puede distinguir dos modelos básicos de madre o padre según su estructura y funcionamiento psicológico. El primer modelo tiene como principal característica que su Niño acepta a la hija o al hijo, encuentra placer en la relación y se permite expresar su amor, su Adulto está disponible para atender adecuadamente la situación y el Padre Protector cumple con las funciones de buen cuidador, lo cual disminuye el conflicto existencial de la niña o del niño al que se hacía referencia anteriormente. El segundo modelo se caracteriza principalmente por tener un Niño con problemas de aceptación plena de su hija o hijo porque provoca o remueve algún temor profundo. El resultado es un Niño confuso que perturba al Adulto y unas conductas del Padre Protector desprovistas de calidez auténtica. Respecto de los mensajes que envían estos dos tipos de progenitores, el primero proporciona básicamente mensajes de permisos y el segundo de prohibiciones, aunado a una amenaza de lo que pasará si no acepta el mensaje.

Naturalmente, la persona no solo recibe mensajes de su familia, sino que también durante su proceso de socialización continúa recibiéndolos de muchas personas significativas, de otras instituciones sociales como la educativa y de la sociedad en general. Mediante la incorporación de estos mensajes, que muchas veces pueden ser falsos, la persona llega a la conclusión "yo soy así", que obviamente es una respuesta aprendida en la infancia y una toma de decisión sobre quién es. A esta creencia sobre sí se le conoce como "mito".
Resumiendo, se podría decir que los pasos para que se fije un mito son: la persona recibe unos mensajes que la llevan a experimentar determinadas emociones, luego llega a la conclusión "yo soy así" y posteriormente se comporta en concordancia con esa creencia. Si después la persona toma conciencia de cómo esta decisión afecta su vida, puede cambiar y volver a decidir sobre sí misma mediante un proceso que la lleve a encontrarse con su verdadero yo.

El guión de vida de una persona está basado en mensajes, los cuales constituyen un marco de referencia sobre cómo actuar, relacionarse y vivir. Esos mensajes son de todo tipo e igual pueden promover el éxito o el fracaso, una vida feliz o desafortunada. También se les conoce como mandatos del guión. A continuación se presentan algunos de los más nocivos.

No vivas. Se transmite de forma verbal o mediante actitudes; por ejemplo: "no sé para qué naciste". Algunas actitudes frecuentes son el abandono, la falta de caricias, la privación de cuidados o ignorar por completo a la persona.

No sientas. Con gestos, reproches o críticas directas se le hace entender a la persona que no debe expresar ciertas emociones; por ejemplo: "los hombre no lloran" o "reírse es de tontos". Esto la lleva a concluir que para ser aceptada no debe sentir, lo que significa anular sus sentimientos. No obstante, sentir y no poder expresar lo que se siente genera mucha angustia, lo cual puede provocar la aparición de trastornos psicosomáticos (una alergia que sustituye un llanto reprimido).

Sé loco. Los mensajes de locura también se transmiten de forma verbal o mediante actitudes; por ejemplo: "siempre fuiste y sigues siendo raro", "siempre haces cosas muy locas, vas a terminar encerrado", "tu comportamiento es tan diferente al de tus hermanos, no te entiendo".

No pienses. Cuando la persona expresa lo que piensa y es descalificada o ignorada, pero se le presta atención y obtiene afecto cuando obedece sin cuestionar, 
se le está enviando el mensaje de que no piense. Igual sucede si solicita algún razón y las respuestas que obtiene son simplemente "porque sí" o "porque no". Con este mandato grabado es difícil que la persona se ponga a reflexionar sobre sí misma, su vida o sus inquietudes.

No crezcas. Este mensaje llega generalmente mediante la sobreprotección, con la cual se logra mantener el control sobre la persona impidiendo que esta logre su autonomía.

No seas pequeño. Es el mensaje opuesto al anterior. Se espera que la niña o el niño no satisfagan las necesidades propias de su edad, que se responsabilice y asuma papeles que no le corresponden, con lo cual se trunca la infancia de la persona.

No lo logres. Son mensajes y actitudes mediante los cuales se desvaloriza las cosas que la persona emprende o desea lograr; por ejemplo: "no sé para qué empiezas eso, de seguro no lo vas a terminar". Más tarde en la vida se puede encontrar a esta persona diciendo: "Me gustaría intentarlo, pero de seguro no lo lograré".

No me superes. Algunos progenitores temen perder poder y prestigio frente a sus hijas o hijos, de modo que recurren a la competencia, pues creen, tal vez inconsciente y falsamente, que si les permiten progresar, ellos perderán su valor. De esta forma, se pueden escuchar fases como: "a tu edad yo ya lo había logrado", "tú estás estudiando y luego seguro trabajarás, pero en mi caso fue distinto, trabajaba y estudiaba a la vez, por eso tengo tanta experiencia”.

No seas tú misma o tú mismo. Son los mensajes que transmiten aquellos progenitores que pretenden que sus hijas o hijos renuncien a sus propósitos para complacerlos a ellos; por ejemplo: "tenemos tanta ilusión de que tú seas...", "nos complacería tanto si tú fueras..., si te comportaras...,si pensaras..., si hicieras..., si sintieras...”.

No seas feliz. Son mensajes que comunican que la vida es una miseria y que la felicidad no existe; por ejemplo: "a esta vida no se viene nada más que a sufrir, todo es una desgracia".

En cuanto a los guiones de vida, debido a que son muy comunes a grandes grupos de personas se han podido clasificar. La primera clasificación de guiones la realizó Berne: Triunfador, Perdedor y No Triunfador. Este último corresponde a las personas que ni triunfan ni fracasan. Posteriormente, se habla de otros dos tipos de guiones, los hamárticos (hamartia es el error que conduce al héroe en las tragedias griegas a un final trágico) y los banales. Las personas con el primer tipo de guión han recibido mensajes del tipo no vivas o no pienses. En los guiones banales la persona pasa desapercibida y son propios de la mayoría de la gente. En este no se desarrollan las potencialidades y la sociedad los favorece, dando cierta sensación de seguridad y bienestar. Los guiones banales se programan generalmente de acuerdo con los roles sexuales; es decir, con lo que la cultura dice que tiene que pensar, hacer, sentir y aparentar la persona según sea hombre o mujer. Por lo tanto, cuanto más se parezca el guión al prototipo social, más banal es y la vida se conduce dentro de límites predeterminados.

Berne también definió seis tipos de guiones según su estructura temporal y los relacionó con personajes de la mitología griega. Martorell (2000) los explica de la siguiente manera:

Guiones nunca. Los mensajes de la persona le impiden lograr aquello que le permitiría sentirse bien, así como Tántalo, encadenado mientras a su alrededor estaban los alimentos y el agua que deseaba y no podía alcanzar. La persona con este guión siente que nunca tendrá lo que desea y que está aparentemente al alcance de la demás personas.

Guiones siempre. Las personas con este guión parecen vivir una maldición que las mantiene realizando aquello que las perjudica o les produce infelicidad. Tal es el caso del mito de Aracne, que fue condenada a ser una araña, tejiendo siempre por atreverse a enfrentar a una diosa. 
Guiones hasta que. En este guión la persona se siente obligada a hacer algo, a vivir cierto tipo de vida, con frecuencia penosa, porque creen que hasta que no lo hagan no podrán ser felices o triunfar, igual al héroe mítico Hércules, que sólo fue un dios después de realizar doce trabajos penosos.

Guiones después de. Estos guiones amenazan con algo que ocurrirá después de que pase un tiempo o suceda algo. Por ejemplo, la persona puede sentir que después de que alcance una meta deberá asumir demasiadas responsabilidades o se aburrirá. El personaje mítico que lo representa es Damocles, que fue feliz en su reinado hasta que se dio cuenta de que había una espada suspendida por un delgado hilo sobre su cabeza.

Guiones una y otra vez. Las personas con este guión expresan con frecuencia: "estuve a punto de...", pero fallan una y otra vez, siempre sucede algo que no les permite alcanzar sus propósitos. El personaje mítico que lo ejemplifica es Sísifo, que cada vez que estaba a punto de llevar la roca a la cima del monte, se le caía y tenía que volver a empezar.

Guiones de final abierto. Significa que el guión termina antes de que la persona muera. Estos son básicamente guiones banales que viven, por ejemplo, muchas personas que se jubilan. Los personajes míticos que lo personifican son Filemón y Baucis, que en recompensa por su bondad fueron convertidos en árboles al final de sus vidas, y así puestos a vegetar.

Estos guiones pueden entremezclarse; por ejemplo, una persona puede fracasar una y otra vez porque teme que después de triunfar, nunca será libre.

Las personas incorporan guiones cuando no logran ser ellas mismas, cuando las personas significativas de su vida y el entorno en que se ha desarrollado le han impedido descubrir quiénes son realmente y cuál es su yo real.

\section{Impulsores de la personalidad. Mini-guiones}

Existen otros mensajes de apariencia positiva llamados mensajes de contraguión, los cuales en realidad impulsan conductas que refuerzan el guión. A estos mensajes se le conoce como impulsores de la personalidad o mini-guión. El guión determina qué es lo que la persona hará durante su vida, mientras que el mini-guión indica cómo lo hará. Se han definido cinco impulsores básicos: sé perfecta o perfecto, sé fuerte, inténtalo una y otra vez, date prisa y complace.

Sé perfecta o perfecto. La persona necesita tener bajo su control todos los factores antes de actuar, pero internamente siente que no logra actuar lo suficientemente bien. Se confunde con un detallismo inútil y generalmente experimenta frustración porque es muy difícil que todo lo que se proponga o esté a su alrededor esté perfecto.

Sé fuerte. Para la persona con este impulsor la expresión de cualquier emoción es signo de debilidad, por lo que tiende a ocultar lo que siente, y de igual forma tiene mucha dificultad para solicitar o aceptar ayuda.

Inténtalo una y otra vez. Con este impulsor, la persona siente la necesidad de esforzarse siempre, de estar intentando nuevas alternativas antes de concluir con la anterior, difícilmente alcanzan resultados definitivos, lo cual le sirve para intentarlo otra vez.

Date prisa. La persona considera que la actividad continua y la rapidez son características deseables, buenas en sí mismas, por lo tanto, entre más rápido se concluya lo que se está haciendo, mejor.

Complace. La persona con este impulsor se siente responsable de que las demás personas a su alrededor estén bien, por lo que le cuesta decir que no a peticiones o deseos de alguien. Tiende a olvidarse de sí misma porque primero están las otras personas. 
Lo contrario a estos impulsores son los permisos, que le permiten a la persona liberarse de esas órdenes.

Los permisos para el sé perfecto son: está bien que seas tú misma o tú mismo, no tienes que ser perfecto siempre; las cosas no siempre son perfectas. Para el sé fuerte: está bien expresar las emociones, cuidarte y solicitar ayuda cuando la necesites. Para el inténtalo una y otra vez: está bien que alcances lo que te propones, puedes darlo por terminado, no necesitas estar intentándolo una y otra vez. Para el date prisa: está bien tomarse el tiempo que se necesite para realizar algo, no es necesario estar haciendo cosas constantemente, toma tiempo para ti. Para complace: no tienes que responsabilizarte siempre por el bienestar de otras personas, es bueno que pienses en ti misma y tienes derecho a decir que no.

\section{El abandono del guión}

Para abandonar guiones de vida nocivos se debe necesariamente cuestionar y eliminar los mensajes y mandatos en los que están fundamentados, dejar de jugar juegos psicológicos, aplicar la ley de la abundancia de caricias, modificar posiciones existenciales negativas, abandonar el mito personal y encontrar el yo real. Todo esto puede implicar una ardua tarea, para la realización de la cual resulta de gran importancia que la persona se pueda sentir apoyada en su esfuerzo por lograr un cambio que traerá beneficios a su vida. En este sentido, el aporte de las personas profesionales en Orientación resulta muy valioso.

El Análisis Transaccional y la disciplina de la Orientación coinciden en que el ser humano tiene la capacidad de tomar decisiones adecuadas, buscar y alcanzar su bienestar personal.

\section{Aportes del Análisis Transaccional aplicados en el ámbito educativo desde la disciplina de Orientación}

La educación debe enfocarse en la totalidad de la persona; es decir, la formación no debe centrarse solo en temas académicos, debe tomar en cuenta otras áreas o dimensiones del funcionamiento humano como el afectivo, el moral y el social. Por lo tanto, las actividades de las instituciones educativas deben consistir no solo en realizar procesos de enseñanza-aprendizaje de materias académicas, sino que también deben promover el desarrollo personal integral de sus poblaciones estudiantiles, por cuanto esas instituciones se constituyen en escenarios en los que ocurre una gran parte del proceso de socialización de las personas.

Igual que las instituciones educativas, las familias constituyen otro importante agente de socialización. El estudiantado proviene de diferentes tipos de familias, algunas de las cuales nutren y apoyan a sus hijas e hijos mientras que otras actúan con dureza o las y los ignoran. Todas estas circunstancias diversas afectan el desarrollo personal e influyen en el desenvolvimiento de las y los estudiantes tanto dentro como fuera del salón de clase y en su vida en general. Lo anterior evidencia la necesidad de que tanto las familias como el personal docente comprendan como están formando a las nuevas generaciones y los efectos benéficos o no que esto tiene en el desarrollo psicológico y la vida futura de las personas estudiantes.

En este sentido, también es importante observar que cuanto mayor sea el desarrollo personal que logren alcanzar quienes laboran en la institución educativa, mayor será el apoyo que puedan brindar en la búsqueda del crecimiento personal del estudiantado. Un apoyo que deber ser continuo, colaborativo y profundo. A su vez, la institución educativa, con la guía de las 
y los profesionales en Orientación, puede proporcionar a las familias información valiosa acerca de aspectos centrales para lograr una formación de calidad para sus hijas e hijos, destacando temas como la importancia del apoyo familiar, las características del desarrollo infantil y de la adolescencia y la influencia que la calidad y el tipo de experiencias cognitivas, emocionales, morales y sociales que se vivan durante esas etapas del ciclo vital tiene en el desarrollo integral de la persona.

Se debe concebir la niñez y la adolescencia como etapas importantes y únicas en la vida de una persona, que brindan el fundamento necesario para la vida adulta, además de valorarlas como un tiempo especial de cambios y crecimientos en todas las áreas: biológica, cognitiva, moral y socioemocional. Cabe entonces destacar que desde los ambientes educativos y familiares se debe trabajar con la población estudiantil en aspectos tales como: promover el autoconocimiento, la autonomía y el logro de la identidad, de modo que pueda obtener respuestas a sus preguntas de quién soy y qué haré con mi vida. Se tiene que facilitar un desarrollo moral adecuado ayudando a las y los estudiantes a definir sus propios valores, a comprender los valores de las y los demás y a entender nociones más avanzadas de conceptos como la justicia, la honestidad y la responsabilidad, conforme su razonamiento moral se desarrolla. También se debe fomentar el mejoramiento de la autoestima, que se refiere también a la valoración propia y la autoimagen, las cuales reflejan la confianza y seguridad en sí misma o en sí mismo. Asimismo, hay que favorecer el establecimiento de relaciones cercanas y positivas de modo que les permita sentirse seres valiosos y que reciben aprobación social, intimidad y afecto. De igual manera, se tiene que fomentar la autoconsciencia emocional y el manejo adecuado de las emociones. Además, hay que enseñar a no reprimir estas sino a expresarlas de forma apropiada y a entender las emociones de las otras personas.
Toda la gama de aspectos mencionados puede ser abordada desde la teoría de Análisis Transaccional, complementándola con los aportes de otras teorías, como se analizó anteriormente en este artículo. Este abordaje pueden hacerlo las y los profesionales en Orientación, mediante la realización de procesos con la población estudiantil, el personal de la institución educativa y las familias, para lograr un trabajo conjunto que acreciente los beneficios en pro de un desarrollo armonioso y sano de las nuevas generaciones.

Cabe destacar que una gran mayoría de las instituciones educativas de nuestro país, tanto de primaria como de secundaria, cuenta con profesionales en Orientación. Durante su formación profesional en la Universidad de Costa Rica, estas y estos profesionales adquieren conocimientos sobre la teoría de Análisis Transaccional que les permite llevarla a la práctica en su desempeño laboral. Las personas profesionales en Orientación pueden aplicar esta teoría empleando las distintas modalidades que comúnmente se utilizan en esta disciplina: orientación individual, orientación personal grupal, orientación colectiva y otras como talleres.

Algunos de los aportes basados en el Análisis Transaccional que se pueden aplicar desde la Orientación son:

Fomentar el sentido del valor humano, enseñando que es importante diferenciar las conductas inadecuadas o problemas de la persona misma, a fin de proteger su dignidad e integridad personal.

Fomentar la vivencia de valores tales como el respeto hacia sí misma o sí mismo y hacia las demás personas, la igualdad, la justicia, la tolerancia, la honestidad, la autenticidad y la autonomía.

Facilitar, mediante procesos de enseñanza-aprendizaje, la modificación de aquellas conductas, emociones y cogniciones nocivas que fueron aprendidas durante el proceso de socialización. Enseñar a las personas una forma más sana y realista de verse a sí mismas, a las otras personas y 
a la vida en general, liberándose de esquemas mentales que limitan su autonomía y su desarrollo personal.

Facilitar el autoconocimiento mediante la enseñanza del análisis estructural y funcional de la personalidad, lo cual es posible gracias al lenguaje sencillo y comprensible de esta teoría, que permite que las personas puedan autoanalizarse, entender su conducta y expresar de forma adecuada los distintos estados emocionales de su yo; es decir, emplear todas las dimensiones de su personalidad y finalmente poder responder a las preguntas: ¿quién soy?, ¿por qué actúo de esta forma? y ¿cómo llegué a ello?

Fomentar en las personas el empleo del estado Adulto de su yo, facilitando el aprendizaje de aspectos tales como: el proceso de toma de decisiones autónomas; la evaluación de posibles consecuencias antes de actuar; asumir la responsabilidad de sus acciones, pensamientos y emociones; elaborar un proyecto de vida basado en objetivos y metas realistas que den sentido y significado a su existencia; tener una visión clara de su escala de valores; buscar soluciones apropiadas a los problemas; deshacerse de mensajes nocivos provenientes de su Padre Crítico o de su Niño, o del Padre Crítico o del Niño de otras personas y aplicar sus capacidades de razonamiento y creatividad.

Facilitar procesos que ayuden a las personas a eliminar actitudes y conductas negativas provenientes de sus estados del yo, tales como: las críticas destructivas, los prejuicios, las desvalorizaciones, las conductas agresivas o represivas, provenientes del Padre Crítico; la sobreprotección y el olvido de sí, provenientes del Padre Nutricio; el logro de propósitos sin tomar en cuenta los derechos o sentimientos de otras personas y la represión de las emociones, provenientes de un Adulto contaminado; el retraimiento, el temor de actuar u opinar por temor a la crítica, la expresión de conductas desproporcionadas y la hostilidad, provenientes del Niño Adaptado Sumiso Rebelde; las manifestaciones inadecuadas de las emociones y conductas egocéntricas provenientes del Niño Natural Libre; la manipulación, el egoísmo y la mentira provenientes del Niño Creativo o Pequeño Profesor.

Fomentar en las personas la adopción de la posición existencia "yo estoy bien y tú estás bien", dejando atrás papeles de víctimas y sentimientos de impotencia, para llegar a la conclusión de que son valiosas, igual que su vida, las otras personas y la vida de estas.

Facilitar la expresión de emociones auténticas, tomando conciencia de estas, encontrando formas adecuadas de manifestarlas y dejando de lado aquellas emociones falsas, elásticas o parásitas.

Promover el abandono de la Ley de la Economía de Caricias y, por el contrario, fomentar el empleo de la Ley de Abundancia de Caricias, para el bienestar propio y el de las personas con quienes se relaciona.

Facilitar el mejoramiento y la calidad de las relaciones interpersonales mediante la enseñanza del análisis de transacciones, que permite comprender a las personas cuáles estados de su yo están empleando en distintas transacciones, de qué tipo de transacción se trata, cuál es su significado y que puedan decidir abandonar aquellas transacciones que resultan nocivas, que las llevan a sentirse mal y a hacer sentir mal a otras personas, sobre todo aquellas que conducen a juegos psicológicos.

Facilitar y enseñar formas apropiadas de abandonar juegos psicológicos entre las personas, que las mantienen desempeñando papeles de Víctimas, Salvadoras o Perseguidoras y que las conducen a sentirse mal, a desarrollar conductas de dependencia, a desgastarse emocionalmente, a perder el tiempo y a crear climas profundamente desfavorables para relaciones interpersonales que podrían ser sanas, íntimas, auténticas, abiertas y sinceras.

Enseñar a las personas, sobre todo a las madres y padres de familia y al personal de las instituciones educativas, a enviar 
más mensajes positivos, de permisos, que nocivos, de prohibiciones o amenazas, sobre todo si son mensajes falsos, etiquetas que llevan a la persona a crear un "mito" sobre sí misma, a la conclusión de que ella es así, a actuar en concordancia y en el peor de los casos a impedirle conocer su verdadero yo.

Facilitar procesos mediante los cuales las personas puedan entender el o los guiones de vida que están viviendo, cómo pudieron surgir a partir de mensajes y mandatos recibidos, cuáles son los impulsores que mantienen ese o esos guiones, identificar cómo se sienten dentro de estos, hacia dónde las conducen y determinar si desean continuar dentro de un guión preestablecido o formular su propio proyecto de vida. Para lograr lo anterior, también es necesario enseñar a las personas lo que se debe hacer para poder abandonar el guión de vida que no se desea.

\section{Conclusiones}

De acuerdo con todo lo analizado, la teoría de Análisis Transaccional, por ser una teoría tan amplia e integral, se convierte en un instrumento de enorme relevancia al servicio de las instituciones educativas en su propósito por promover una formación de calidad para su población estudiantil, la cual resulta de beneficio también para el personal de la institución y las familias del estudiantado.

Es importante señalar que para trabajar todos los temas mencionados con las distintas poblaciones: estudiantes, personal docente y administrativo y familias, también pueden emplearse los aportes que ofrecen otras teorías y enfoques, dado que, como se señaló, una de las características del Análisis Transaccional es que facilita la integración, lo cual permite una mayor flexibilidad en su empleo y una intervención profesional más amplia y profunda.

Finalmente, es importante subrayar que cuando se brindan oportunidades para que las personas se desarrollen en un entorno caracterizado por el amor, la aceptación, la protección y las caricias positivas, tienden a estar bien, a valorarse y valorar a las otras personas, a desarrollar sus potencialidades, a actuar de forma autónoma y a auto-realizarse.

\section{Referencias bibliográficas}

Berne, E. (1961). Transactional Analysis in Psychotherapy. New York: Grove Press Inc.

Berne, E. (1983). Introducción al tratamiento de grupo. (20 edición). Barcelona: Grijalbo.

Berne, E. (1988). Juegos en que participamos. Psicología de las relaciones humanas. Buenos Aires: Jaime Vergara Editor. (co-edición de Editorial Diana de México). Reimpresión.

Camino, J, y Coca, A. (2006). Una teoría de las emociones para el Análisis Transaccional. Revista de Análisis Transaccional y Psicología Humanista. $N^{o} 55$. Recuperado de http://www.arantxa-coca.con/archivos/p001.pdf

Coca, A. (2004). Los juegos de poder entre el psicoterapeuta y el niño en la hora del diagnóstico. Revista de Análisis Transaccional y Psicología Humanista. $N^{\circ} 51$. Recuperado de http://www.arantxa-coca.com/archivos/p003.pdf

Corey, G. (1989). Theory and practice of group counseling. California: Brooks/ Cole Publishing Company.

Feixas, G. y Miró, M. (1993). Aproximaciones a la psicoterapia. Una introducción a los tratamientos psicológicos. Barcelona: Paidós.

Garrido, M. y García, J. (1994). Psicoterapia. Modelos contemporáneos y aplicaciones. Valencia: Promolibro.

Giardino, R. (2010). Conceptos centrales del Análisis Transaccional. Recuperado de http://www.monografias.com/.../el- 
analisis-transaccional/el-analisistransaccional.pdf

James, M. y Jongeward, D. (1976). Nacidos para triunfar: Análisis Transaccional con experimentos Gestalt. México: Fondo Educativo Interamericano.

Jongeward, D. (1980). En busca del éxito. Análisis Transaccional en la práctica. México: Limusa.

Martorell, J. (2000). ¿Qué nos pasa una y otra vez? Madrid: Marsiega.

Naranjo, M. (2004). Enfoques conductistas, cognitivos y racional-emotivos. San José: Editorial Universidad de Costa Rica.

Naranjo. M. (2004). Enfoques humanísticoexistenciales y un modelo ecléctico. San José: Editorial Universidad de Costa Rica.

Oller, J. (2005). Las emociones en el Análisis Transaccional, relacionadas con los estados del yo. Recuperado de http://www.bernecomunicacion.net/ pdf/berne.pdf

Opi, J. y Beltrán, M.. (2005). La dieta del P.A.N. Una fórmula para disfrutar de la vida. Barcelona: Amat.

Rogers, C. (1961). On Becoming a Person. Boston: Hooghton Miffling.

Santrock, J. (2002). Psicología de la educación. México: Mc Graw Hill.
Senlle, A. (1991). ¿Quiere sentirse bien? Cambie su vida con el Análisis Transaccional. Barcelona: CEAC, S.A. Steiner, C. (1980). Libretos en que participamos. México: Diana.

Steiner, C. (1991). Los guiones que vivimos. Análisis Transaccional de los Guiones de la Vida. Barcelona: Kairós.

Steiner, C. (1997). El Análisis Transaccional en la era de la información. Transactional Analysis Journal, Vol. 27, 1. Recuperado de http://www.bernecomunicacon.net/pdf/berne9.pdf

Thomas, P. (2000). Análisis Transaccional. Relaciones humanas y autorrealización personal. San José: EUNED.

Valbuena, F. (2004). El Análisis Transaccional (propiamente dicho), de Eric Berne. Revista Digital El Catoblepas: 34: 16-55. Recuperado de http://www.infonegociacion.net/pdf/ elcatoblepas5.pdf

Zinker, J. (2000). El proceso creativo en la Terapia gestáltica. México: Paidós. 